\title{
Fitness landscapes in natural rocks system evolution: A conceptual DFT treatment $^{\#}$
}

\author{
SOMA DULEY ${ }^{\mathrm{a}}$, JEAN-LOUIS VIGNERESSE ${ }^{\mathrm{b}, *}$ and PRATIM KUMAR CHATTARAJ ${ }^{\mathrm{a}, *}$ \\ ${ }^{a}$ Department of Chemistry and Center for Theoretical Studies, Indian Institute of Technology Kharagpur, \\ Kharagpur 721 302, India \\ bancy-Université, UMR 7566 G2R, BP 23, 54501 Vandoeuvre cédex, France \\ e-mail: jean-louis.vigneresse@g2r.uhp-nancy.fr; pkc@chem.iitkgp.ernet.in
}

\begin{abstract}
The chemical reactivity descriptors, such as electronegativity, hardness and electrophilicity of major oxides computed from density functional theory are reported in this paper. These parameters are plotted within a fitness landscape diagram, showing that the principles of minimum electrophilicity (MEP) and maximum hardness (MHP) act as guides towards the region of higher stability. The diagrams indicate the trends and the parameters that control the evolution of natural rocks. Application of the principle S-bearing copper compounds shows the possible and preferred combinations of elements, that give rise to compounds observed during ore formation.
\end{abstract}

Keywords. Fitness landscape; maximum hardness principle; minimum electrophilicity principle; natural rocks evolution.

\section{Introduction}

The various parameters developed by the density functional theory ${ }^{1}$ (DFT) of chemical reactivity such as the hard-soft acid-base (HSAB) concepts ${ }^{2}$ have been found to be useful in analysing a variety of chemical reactions. They are mostly based on the possibility of a given element to share electrons, thus separating bases or electron donors from acids or electron acceptors. These parameters enable the quantification of the ability of a specific element to attract other elements. The parameter are electronegativity ${ }^{3}(\chi)$, chemical hardness ${ }^{4}(\eta)$ and electrophilicity ${ }^{5}(\omega)$.

There are two major principles in the conceptual DFT, namely, the maximum hardness principle ${ }^{6}$ (MHP) and the minimum electrophilicity principle ${ }^{7}$ (MEP). As indicated by their names, they state that a chemical reaction should evolve toward a state of maximum hardness and/or toward that of minimum electrophilicity. Consequently, plotting elements or compounds onto an electrophilicity versus hardness diagram constitute a fitness landscape into which reactions tend to adopt either or both of the preceding principles. Such diagrams ${ }^{8}$ provide information on what drives the chemical reactions. Indeed they indicate local energetic minima and maxima, respectively, to and fro which the chemical system either gravitates or tries to escape to go to a

\footnotetext{
\#Dedicated to Prof. N Sathyamurthy on his 60th birthday

*For correspondence
}

more stable situation. Thus, these diagrams are indicative of the probable evolution of the system under natural conditions, when no other factor has influence. The situation is of interest when naturally evolving chemical systems, such as igneous rock evolution is considered. Igneous rocks, such as granites or basalts originate from magmas, i.e., silicate melts that evolve due to pressure and temperature conditions, causing crystallization of minerals. The formation of minerals consequently removes the constituting elements from the silicate melt, changing their respective abundance and thus driving the chemical character of the residual melt. As a consequence, the igneous rocks that later intrude the Earth crust vary in composition, forming two major types called mafic, when the major mineral is olivine, a ferro-magnesian silicate, along with pyroxenes and it is called felsic, when quartz, or silica is present, along with plagioclases and micas. The former type is observed in rocks coming from the mantle and the oceanic crust, forming basalts and gabbros from mantle peridotites. The second type is mostly observed in the continental crust, forming granodiorites and granites, depending on the various interactions the magma has with the surrounding crust through contamination and assimilation. These two types, one driven by $\mathrm{Fe}$ enrichment, and the second by silica enrichment, are often called the Fenner and Bowen trends, ${ }^{9}$ respectively. These trends have long been demonstrated by experiments, but never received any theoretical proof or underlying concepts. The following paper rapidly 
resumes the HSAB concepts and descriptors. Then it introduces an application of the fitness landscape diagrams to natural rocks suites and to $\mathrm{Cu}$ ore formation resulting from $\mathrm{S}$-bearing compounds.

\section{Conceptual DFT}

Electronegativity $^{3}(\chi)$ is a thermodynamic quantity which is the chemical potential $(\mu)$ with a change in sign. It represents the power of an element to attract electrons and it measures the ability of one element to diffuse and to contribute to energy variations when one electron is added. Chemical hardness ${ }^{4}(\eta)$ measures the chemical activity of an element by determining the resistance to charge transfer in electron number. Chemical potential (negative of electronegativity) and hardness are the first and second derivatives of the total energy, respectively and may be expressed as a function of the electron density, ${ }^{1}$ with respect to the number of electrons when the external potential is kept constant.

The electronegativity ${ }^{3}(\chi)$ and the chemical hardness $^{4}(\eta)$, for an $\mathrm{N}$-electron system with total energy $\mathrm{E}$ and external potential $\mathrm{v}(\mathbf{r})$, are expressed as follows

$$
\chi=-\mu=-\left(\frac{\partial E}{\partial N}\right)_{\nu(\mathbf{r})}
$$

and

$$
\eta=\left(\frac{\partial^{2} E}{\partial N^{2}}\right)_{v(\mathbf{r})} .
$$

By applying finite difference approximations to the above derivatives one can express the electronegativity $(\chi)$ and the chemical hardness $(\eta)$ in terms of the ionization potential $(I P)$ and the electron affinity $(E A)$ as

$$
\chi=-\mu=\left(\frac{I P+E A}{2}\right)
$$

and

$$
\eta=I P-E A,
$$

where the $I P$ and the $E A$ are expressed in terms of the energy of an N-electron system, $E(N)$, as

$$
I P=E(N-1)-E(N)
$$

and

$$
E A=E(N)-E(N+1) .
$$

Their values determine the hard, soft and borderline acids and bases. Electrophilicity ${ }^{5}(\omega)$ combines these two descriptors through $\omega=0.5 * \chi^{2} / \eta$ and it measures the deficiency in electron of one element. ${ }^{5}$ It can be considered as the analogue of the classical electrical power $W=V^{2} / R$, in which the potential $V$ would be analogous to electronegativity and the resistance $R$ would be to the hardness. ${ }^{4}$ Electrophilicity determines the capacity of one element to promote a soft or a covalent reaction. ${ }^{5}$ It describes the stabilization in energy when the system acquires an additional electronic charge or the resistance to exchange electrons with the environment. Radicals are designated as being electrophiles when they attack the reaction sites of relatively high electron density. Electrophile acids act as oxidizing agents since they accept electrons during an acid-base reaction. Since several definitions exist for electronegativity along with the corresponding units, we recomputed these descriptors for some simple elements and oxides that are commonly used in geochemistry. We adopted standard formulas for various reactivity descriptors and the associated electronic structure principles within the conceptual density functional theory ${ }^{1}$ for major oxides (table 1).

We used the B3LYP/6-311+G(d) level of theory, with a Gaussian code. ${ }^{10}$ It allows estimating the successive ionization potential and electron affinity of an element or any compound, thus providing values of electronegativity $^{3}(\chi)$, hardness ${ }^{4}(\eta)$ and electrophilicity. ${ }^{5}$ Hence, the electron density is central in DFT, and the transfer of electrons from one element to another is the basis of most chemical reactions. The calculated values can be compared to the measured values of natural elements, but of greater interest, values can be estimated for any kind of compound with different oxides, oxysalts or other chemical compounds.

These values of major oxides are then combined to determine the descriptors of complex systems, such as melt or fluid phase in a magma. This is in accordance to the electronegativity equalization principle ${ }^{11}$ which states that the electronegativities adjust at equilibrium, similar to the equalization of the chemical potential of the constituting elements that enter into the compounds.

Table 1. Electronegativity $(\chi)$, hardness $(\eta)$ and electrophilicity $(\omega)$ values (in $\mathrm{eV}$ ) for major oxides recomputed from DFT.

\begin{tabular}{lccc}
\hline Oxide & $\chi(\mathrm{eV})$ & $\eta(\mathrm{eV})$ & $\omega(\mathrm{eV})$ \\
\hline $\mathrm{SiO}_{2}$ & 7.12 & 5.46 & 4.64 \\
$\mathrm{TiO}_{2}$ & 5.76 & 3.86 & 4.30 \\
$\mathrm{Al}_{2} \mathrm{O}_{3}$ & 5.98 & 3.85 & 4.64 \\
$\mathrm{FeO}$ & 5.28 & 3.37 & 4.14 \\
$\mathrm{Fe}_{2} \mathrm{O}_{3}$ & 6.01 & 2.95 & 6.12 \\
$\mathrm{MnO}$ & 4.79 & 3.49 & 3.29 \\
$\mathrm{MgO}$ & 4.90 & 2.95 & 4.07 \\
$\mathrm{CaO}$ & 3.97 & 3.06 & 2.58 \\
$\mathrm{Na} 2 \mathrm{O}$ & 2.67 & 2.33 & 1.53 \\
$\mathrm{~K}_{2} \mathrm{O}$ & 2.37 & 2.2 & 1.28 \\
$\mathrm{P}_{2} \mathrm{O}_{5}$ & 7.13 & 5.25 & 4.84 \\
$\mathrm{H}_{2} \mathrm{O}$ & 5.05 & 7.56 & 1.69 \\
\hline
\end{tabular}


This assumption is valid assuming the ionic state of the melt, or of the fluid, or vapour phase. It correlates with the large electronegativity difference between elements, suggesting that highly charged elements, i.e., with large electronegativity, remain in ionic bonding when combining with small electronegative anions.

The $\mathrm{MHP}^{6,12}$ and the $\mathrm{MEP}^{7}$ determine how reactions progress allowing hard acids to combine with hard bases to form harder compounds, whereas electrophilicity minimization states that an element or a molecule with large electrophilicity value, or an electrophile, will preferentially react with another molecule or element with a smaller electrophilicity value, or a nucleophile. Combining these two principles that respectively determine positions of maximum stability constitute a map of potential stable regions towards which reactions tend. As a result, they form a fitness landscape in which natural stability paths can be identified. A stable system or a favourable process is generally associated with the maximum hardness and the minimum electrophilicity values. Since the conditions of their validity are not exactly the same, the respective pole may be connected with kinetic stability/local minima and its satisfaction may provide thermodynamic stability/global minimum. This fact deserves a careful scrutiny. It may be mentioned that the natural rock systems behave like thermodynamic open or closed systems and hence a grand potential or a free energy related descriptor would have been more apt. However, the quantum chemical descriptors (defined at 0K) like electronegativity, hardness and electrophilicity may be used to essentially obtain an approximate benchmark.

\section{Computational details}

The molecular geometry of all the systems are optimized at the B3LYP/6-311+G(d) level of theory and the number of imaginary frequency (NIMAG) is zero for all the cases, which confirms their existence at the minima on the potential energy surface. Single point calculations are performed to obtain the energies of $(N \pm 1)$ - electron systems by adopting the corresponding optimized geometry of the N-electron system. The $I P$ and $E A$ values are calculated by using a $\triangle$ SCF method and the electronegativity $(X)$ and chemical hardness $(\eta)$ are computed by using equations (3) and (4).

\section{Application to bulk rock evolution}

The rocks which are commonly formed by silicate minerals that are combinations of the 10 major oxides.
Therefore, plotting a fitness diagram of oxides should determine a limit for the extension of the field of the minerals, that would in turn limit the extension of the field of bulk rocks. Major oxides plot within a triangle with summits $\mathrm{SiO}_{2}, \mathrm{Fe}_{2} \mathrm{O}_{3}$ and $\mathrm{K}_{2} \mathrm{O} . \mathrm{SiO}_{2}$ is the hardest oxide and $\mathrm{K}_{2} \mathrm{O}$ is the softest. In terms of electrophilicity, $\mathrm{Fe}_{2} \mathrm{O}_{3}$ presents the highest value and $\mathrm{K}_{2} \mathrm{O}$ the lowest (figure 1). The position of $\mathrm{Na}_{2} \mathrm{O}$, very close to $\mathrm{K}_{2} \mathrm{O}$, makes the alkaline elements a pole of the triangle. The position of $\mathrm{FeO}$ is roughly at the intersection of the medians. The medians define three sectors within the mineral triangle, each one having a similar area, scaled in $\chi^{2}$, that is of equivalent chemical potential. In addition, the median between $\mathrm{FeO}$ and $\mathrm{Fe}_{2} \mathrm{O}_{3}$, marked by an increase in electrophilicity and a very small increase in hardness is indicative of the redox conditions of the system. Reciprocally, an increase in the redox conditions should be marked by an increase in electrophilicity. Silica is naturally a pole for minerals, for its highest hardness and electrophilicity (figure 2). Olivine is another pole, with the two end-members forsterite $\left(\mathrm{Mg}_{2} \mathrm{SiO}_{4}\right)$ and fayalite $\left(\mathrm{Fe}_{2} \mathrm{SiO}_{4}\right)$ close together. The third pole is provided

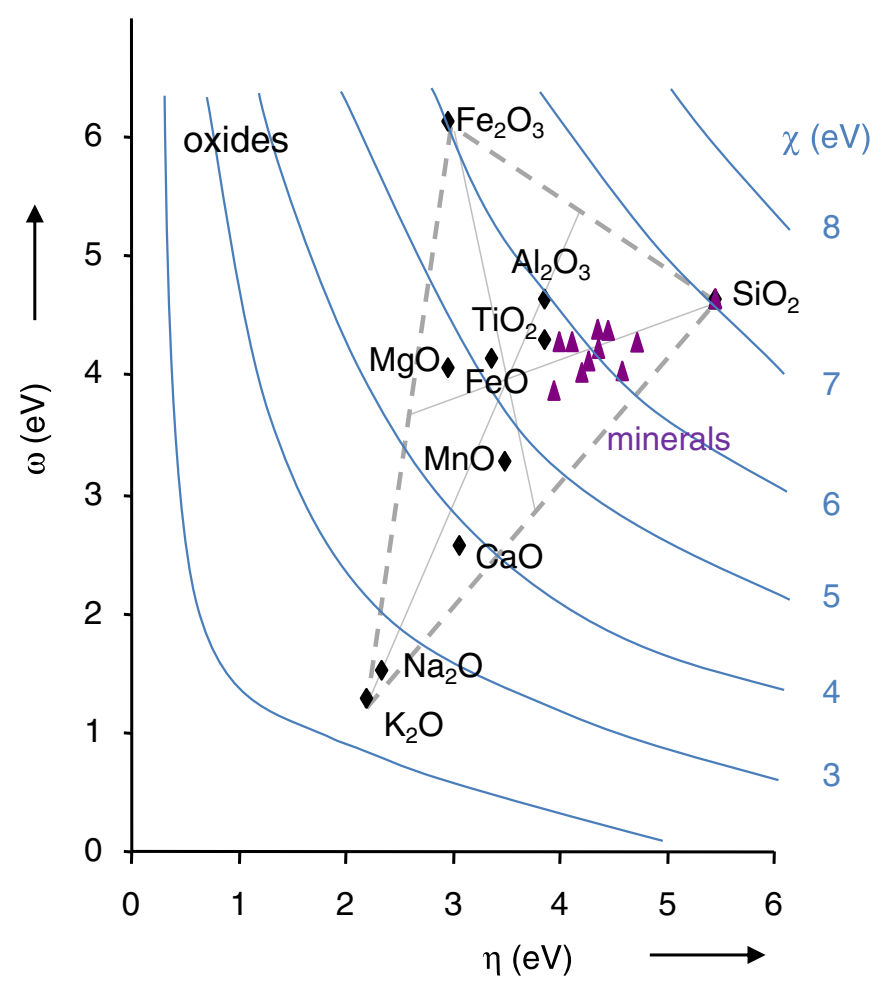

Figure 1. Electrophilicity $(\mathrm{eV})$ versus hardness $(\mathrm{eV})$ for major oxides used in Earth Sciences. They plot within a triangle limited by $\mathrm{Fe}_{2} \mathrm{O}_{3}, \mathrm{SiO}_{2}$ and alkali $\left(\mathrm{Na}_{2} \mathrm{O}\right.$ and $\left.\mathrm{K}_{2} \mathrm{O}\right)$. Within the triangle, most common minerals are represented by triangles. Within the landscape diagram, values of electronegativity (also in $\mathrm{eV}$ ) are represented by thin lines. 


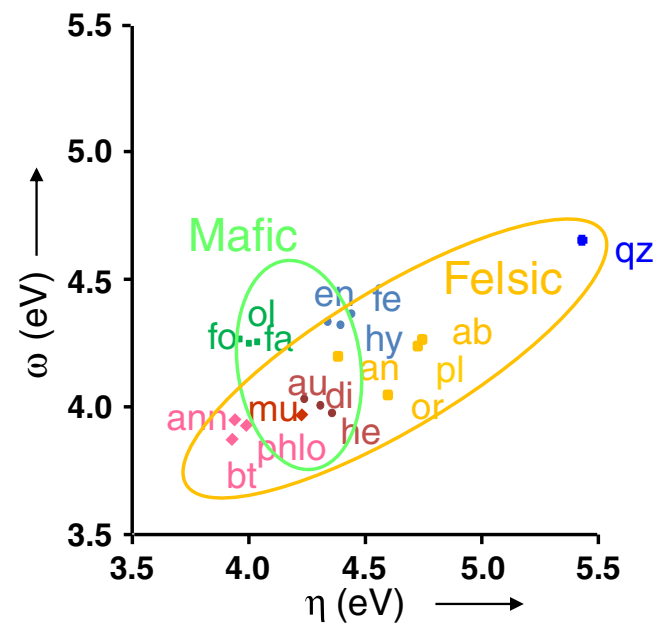

Figure 2. Electrophilicity (eV) versus hardness $(\mathrm{eV})$ for major minerals. Symbols are cross: quartz (qz), blue squares: clinopyroxenes and pale blue: orthopyroxebnes, plain squares for plagioclases from albite, anorthite, orthoclase and leucite, green squares for olivine, from fayalite to forsterite, lozenges for muscovite, and pale lozenges for biotites from annite to phlogopite. The mafic and felsic trends are indicated.

by the leucite, or $\mathrm{KAlSi}_{2} \mathrm{O}_{6}$, that presents more potassium relative to silica than orthoclase, or $\mathrm{KAlSi}_{3} \mathrm{O}_{8}$, the common K-feldspar. Plagioclase (albite and anorthite), lies more or less on a line in between leucite and silica. Clinopyroxenes (augite, diopside, hedenbergite) and orthopyroxenes (enstatite, ferrosilite, hypersthene show low hardness and range in electrophilicity between olivine and leucite. Because of their short range in hardness, olivine and pyroxenes partly control the evolution of mafic rocks under a changing electrophilicity. Conversely, the two poles of silica and alkaline minerals control the change in hardness in felsic and alkaline rocks. Within the triangle formed by the minerals, the line between olivine and orthoclase presents a nearly constant electronegativity, at $5.8 \mathrm{eV}$, i.e., with similar chemical potential. The other sides of the triangle show variation in electronegativity when compared to $7.12 \mathrm{eV}$ value of the silica pole.

Major trends are seen for mafic, felsic and alkaline rocks. They differentiate the rocks originating from oceanic to those from continental settings. Felsic rocks, mainly granitoids naturally point toward silica, as expected from their silica content above $55 \%$ vol. The variation in electrophilicity is low, whereas hardness change is high. Alkaline magma, such as those found in rift environments, show an increase in silica content, from about 38 to $55 \%$. However, the slope of this trend in a fitness landscape diagram changes as soon as quartz tholeiitic rocks are present. Mostly for alkaline rocks, such as nephelinites and basanites, the trend is toward lower hardness and electrophilicity. The case of oceanic rocks is quite different. Since the quartz pole does not have much influence, the observed trend is at high angle of the two preceding ones, under nearly constant hardness, but varying electrophilicity. When the variation in hardness is less than that in electrophilicity an MEP path is generally preferred whereas an MHP path is followed when the case is reversed.

The dichotomy in the description of the systems forces one to differently consider the evolution of continental and oceanic magmas. The Gibbs description for a closed system considers the variations in pressure, entropy and number of moles. However, the system is partly a solid solution between $\mathrm{Ca}$ and $\mathrm{Na}$ plagioclases on one hand and between $\mathrm{Fe}$ and $\mathrm{Mg}$ silicates on the other hand, through olivine, pyroxenes and in a lesser extent amphiboles and biotites. Pressure and temperature variations first follow an adiabatic path during ascent and then follow a eutectic curve. Conversely, the description of rocks evolution, when originating in continental settings, shows larger variation in hardness, implying also variation in eletronegativity, i.e., in chemical potential. The introduction of alkalines, especially $\mathrm{K}$ also significantly modifies rocks reactivities during mineral formation.

This would explain the paths toward MEP and MHP as suggested in the Bowen ${ }^{13}$ and Fenner ${ }^{14}$ series, though they are both used to basalt differentiation. In the Fenner ${ }^{14}$ series for ultramafic and mafic rocks, the components behave as closed systems, in which fluids, essentially water, are stored into minerals with low content $(<2.0 \%$ in back arc basalts and $<0.7 \%$ in MORB). Conversely, continental rocks behave as open systems, because the fluid activity is higher, up to $10 \% \mathrm{H}_{2} \mathrm{O}$, continuous exchange with the surroundings through assimilation, and mixing with mafic or felsic magmas. ${ }^{13}$

\section{Application to $\mathrm{Cu}$-bearing compounds}

Metals occur in very small quantities on the Earth. During melting and magma formation, they are incorporated into the silicate melts and are transported up towards the surface. Depending on various conditions, they may remain in the melt or be associated with a vapour phase called the fluid phase. During this transportation, they may segregate and concentrate, yielding economic ore deposits. These successive processes are complex, and not well understood. Nevertheless, associations between elements and the content of the fluid phase are observed. For instance S-bearing vapour phase, commonly present in some magmatic intrusions, are thought to highly correlate with $\mathrm{Cu}$-bearing minerals, as 


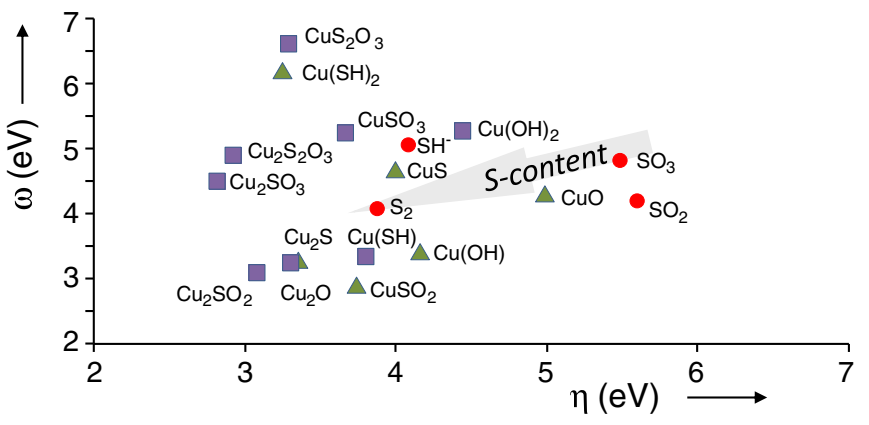

Figure 3. Electrophilicity $(\mathrm{eV})$ versus hardness $(\mathrm{eV})$ diagram for major $\mathrm{S}$-compounds of copper as $\mathrm{Cu}^{+}$and $\mathrm{Cu}^{2+}$. Other main S-compounds such as $\mathrm{SH}^{-}, \mathrm{S}_{2}, \mathrm{SO}_{2}$ and $\mathrm{SO}_{3}$ have also been added for comparison.

observed in the so-called porphyry copper deposits. ${ }^{15}$ These are found in abundance, above subduction zones, such as the western coast of Chile where the largest $\mathrm{Cu}$ deposits are actually mined. ${ }^{16}$ Nevertheless, $\mathrm{Cu}$ association with other elements, such as $\mathrm{Ag}$ or $\mathrm{Au}$ are common. It should be pointed out that these three metals are considered as being soft.

Copper commonly occurs as $\mathrm{Cu}^{+}$and $\mathrm{Cu}^{2+}$, with the high valence state being the hardest, and by far the most electrophilic. We examined and computed the chemical descriptors of all possible compounds including the unstable ones using the ionic compounds of $\mathrm{SH}^{-}, \mathrm{S}^{-}$, $\mathrm{SO}_{2}^{-}$and $\mathrm{S}_{2} \mathrm{O}_{3}^{-}$. These constitute the sequence from the reduced to the oxidized state. In addition, it is extremely easy to calculate the molar content in $\mathrm{S}$ within these compounds, and thus provide an order for the $\mathrm{S}$ content. All this information is plotted within a fitness landscape (figure 3). As expected, the electrophilicity decreases as the hardness increases with the oxidation state. It results that the compounds adopt a curved path, concave toward high electrophilicity as the molar S content increases (figure 3). Values for $\mathrm{Cu}^{+}$are naturally lower than those for $\mathrm{Cu}^{2+}$, but the difference in electrophilicity between them is much lower, about 2 to $3 \mathrm{eV}$, than the difference between the two $\mathrm{Cu}$ cations, about $36 \mathrm{eV}$. When replaced on the field of oxides and magmas, it is interesting to see that the mafic magmas, which present the lower hardness are also on the side of the oxidized compounds. Conversely, the more felsic magmas are on the side of the reduced compounds. This fits the common subdivision of granitoids into the ilmenite $(\mathrm{FeO}$, $\left.\mathrm{TiO}_{2}\right)$ and magnetite $\left(\mathrm{FeO}, \mathrm{Fe}_{2} \mathrm{O}_{3}\right)$ series. ${ }^{7}$

\section{Conclusions}

The application of the conceptual DFT certainly brings new insights into the chemical evolution of complex processes such as the evolution of natural igneous rocks. These evolve as a complex system and the abundance of major oxides does not help in defining a theoretical evolution, except by doing experiments. The application of fitness landscape diagrams that uses both electrophilicity and hardness represents a valuable method towards the determination of chemical evolution of complex systems. They rely on two basic principles that rule the HSAB concepts.

\section{Acknowledgements}

We thank Professor Saibal Gupta for constructive criticism. JLV acknowledges a brief stay in Indian Institute of Technology, Kharagpur, granted by the CTS (Center for Theoretical Studies), that allowed fruitful discussions. PKC thanks the Department of Science and Technology (DST), New Delhi for J C Bose Fellowship.

\section{References}

1. (a) Parr R G and Yang W 1989 Density Functional Theory of Atoms and Molecules (Oxford: Oxford University Press); (b) Geerlings P, De Proft F and Langenaeker W 2003 Chem. Rev. 103 1793; (c) Chattaraj P K and Giri S 2009 Annu. Rep. Prog. Chem. Sect. C 105 13; (d) Chattaraj P K 2009 Chemical reactivity theory: A density functional view Eds. Taylor \& Francis, CRC Press, Florida

2. (a) Chattaraj P K, Lee H and Parr R G 1991 J. Am. Chem. Soc. 113 1855; (b) Pearson R G 1990 Coord. Chem. Rev. 100 403; (c) Chattaraj P K and Schleyer P v R $1994 \mathrm{~J}$. Am. Chem. Soc. 116 1067; (d) Pearson R G 1973 Hard and soft acids and bases Ed. Dowden, Hutchinson \& Ross: Stroudsberg, PA; (e) Hancock R D and Martell A E 1996 J. Chem. Educ. 73 654; (f) Chattaraj P K and Maiti B 2003 J. Am. Chem. Soc. 125 2705; (g) Pearson R G and Chattaraj P K 2008 Chemtracts: Inorg. Chem. 211

3. (a) Pauling L 1960 The nature of the chemical bond (3rd ed.; Ithaca, New York: Cornell University Press); (b) Parr R G, Donnelly R A, Levy M and Palke W E 1987 J. Chem. Phys. 68 3801; (c) Chattaraj P K 1992 J. Indian Chem. Soc. 69173

4. (a) Parr R G and Pearson R G 1983 J. Am. Chem. Soc. 105 7512; (b) Pearson R G 1997 Chemical hardness: applications from molecules to solids (Wiley-VCH: Weinheim)

5. (a) Parr R G, Szentpaly L v and Liu S 1999 J. Am. Chem. Soc. 121 1922; (b) Chattaraj P K, Sarkar U and Roy D R 2006 Chem. Rev. 106 2065; (c) Chattaraj P K and Roy D R 2007 Chem. Rev. 107 PR46; (d) Chattaraj P K, Giri S and Duley S 2011 Chem. Rev. 111 PR43

6. (a) Pearson R G 1987 J. Chem. Edu. 64 561; (b) Pearson R G 1999 J. Chem. Edu. 76 267; (c) Parr R G and Chattaraj P K 1991 J. Am. Chem. Soc. 113 1854; (d) Chattaraj P K, Liu G H and Parr R G 1995 Chem. Phys. 
Lett. 237 171; (e) Chattaraj P K 1996 Proc. Indian Natl. Sci. Acad. Part A 62 513; (h) Ayers P W and Parr R G 2000 J. Am. Chem. Soc. 122 2010; (i) Pearson R G 1993 Acc. Chem. Res. 26250

7. (a) Chamorro E, Chattaraj P K and Fuentealba P 2003 J. Phys. Chem. A 107 7068; (b) Parthasarathi R, Elango M., Subramanian V and Chattaraj P K 2005 Theor. Chem. Acc. 113257

8. Kauffman S A 1995 At home in the Universe: The search for laws of self-organization and complexity, Oxford University Press, New York, 321

9. McBirney A R 1993 Igneous petrology, Jones \& Bartlett, Boston, 572
10. Gaussian 032003 Revision B.03; Gaussian, Inc.: Pittsburgh, PA

11. (a) Sanderson R T 1951 Science 114 670; (b) 1954 J. Chem. Educ. 31 238; (c) 1955 Science 121207

12. Pearson R G 1993 Acc. Chem. Res. 26250

13. Bowen N L 1922 J. Geol. 30177

14. Fenner C N 1937 J. Geol. 45158

15. Halter W E, Bain N, Becker K, Heinrich CA, Landtwing M, VonQuadt A, Clark A H, Sasso A M, Bissig T and Tosdal R M 2004 J. Volc. Geoth. Res. 1361

16. Richards J P 2003 Eco. Geol. 981515

17. Ishihara S 2004 Trans. R. Soc. Edinburgh: Earth Sci. 9523 